\title{
Working Memory and Speed of Information Processing in Chronic Khat Users: Preliminary Findings
}

\author{
Richard Hoffman Mustafa al'Absi \\ Department of Biobehavioral Health and Population Science, University of Minnesota Medical School, \\ Duluth, Minn., USA
}

\section{Key Words}

Khat $\cdot$ Cathinone $\cdot$ Working memory $\cdot$ Processing speed

\begin{abstract}
To date there are very few laboratory data available regarding the long-term effect of the psychostimulant khat on human neurocognitive functioning. The purpose of the present study was to assess whether chronic khat users would demonstrate impairments in working memory and speed of information processing compared to control subjects. Working memory was assessed using the forward and backward digit span test. Speed of information processing was assessed using the Digit Symbol Substitution Test. Results of the present study indicate that chronic khat use may have a long-term deleterious effect on working memory, particularly on digit backwards measures of short-term/working memory. The finding is consistent with results seen by several investigators in samples of methamphetamine users.
\end{abstract}

Copyright $\odot 2012$ S. Karger AG, Basel

\section{Introduction}

Khat (Catha edulis Forsk) is a stimulant leaf that is widely used in countries bordering the Red Sea, along the east coast of Africa and in west Asia [1], as well as immi- grant communities in Western countries, primarily Great Britain, the Netherlands and the USA [2]. Users of khat report feeling as if they are able to think more clearly and more quickly while chewing khat and also report increased energy, increased confidence, a general sense of well-being, decreased hunger and fatigue and the increased ability to easily converse with others. Other selfreported acute effects of khat include increased levels of alertness, enhanced ability to concentrate, friendliness, contentment and flow of ideas [3]. This is usually followed by excessive tension, anxiety, emotional instability, irritability and restlessness within $2 \mathrm{~h}$, followed by feelings of low mood, numbness, lack of concentration, sluggishness and insomnia.

Khat leaves contain cathinone, a psychostimulant that is similar in structure and pharmacological activity to amphetamine [4]. Due to these similarities, cathinone has been called a 'natural amphetamine'. Cathinone has been characterized as an amphetamine-like sympathomimetic amine [5] with a half-life of approximately $3 \mathrm{~h}$ in humans [6]. In addition to cathinone, cathine (or d-norpseudoephedrine) has been identified as an additional psychoactive ingredient in khat [7], and cathine has also been noted to have psychostimulant properties, although cathinone appears to be only half as potent as amphetamine and cathine is roughly $7-10$ times less potent than amphetamine. The acute effects of the cathamines (cathi-

\section{KARGER}

Fax +41613061234

E-Mail karger@karger.ch

www.karger.com
(C) 2012 S. Karger AG, Basel

$1022-6877 / 13 / 0191-0001 \$ 38.00 / 0$

Accessible online at:

www.karger.com/ear
Richard Hoffman, $\mathrm{PhD}$ and Mustafa al'Absi, PhD

Department of Biobehavioral Health and Population Science

University of Minnesota Medical School

Duluth, MN 55812 (USA)

E-Mail rhoffman@d.umn.edu, malabsi@d.umn.edu 
none and cathine) on neurotransmission are basically comparable to those induced by amphetamine [8], although of much lesser magnitude due to the decreased potency noted above. These compounds apparently act by increasing dopamine, 5 -hydroxytryptamine and noradrenaline release [3]. Dopamine is produced in both the substantia nigra and the ventral tegmental area (VTA). The VTA projects to the ventral striatum and limbic structures and may serve an important role in rewardrelated behaviors. The VTA also projects into the frontal cortex, which plays a role in a variety of cognitive processes including attention and working memory. It is hypothesized that excessive dopaminergic activity could result from long-term use of amphetamines or amphetamine-like substances such as khat to negatively affect working memory functioning. Similar to amphetamine, cathinone has been observed to inhibit the activity of dopamine, noradrenaline and 5-hydroxytryptamine transporters in animal models at the synaptic level in the striatum $[9,10]$. The well-developed scientific literature examining the acute and chronic neurobehavioral effects of amphetamine and methamphetamine can therefore provide a general model to guide future research related to the acute and chronic effects of khat use. To date, there are very few laboratory data available regarding the effect of khat use on human neurocognitive functioning.

Colzato et al. [11] recently reported that khat users demonstrate impaired inhibitory control compared to nonusers, specifically demonstrating significantly more time to inhibit responses to stop signals on a computeradministered stop signal task. In a subsequent study, this same research group [12] reported that a small sample of 20 regular khat users demonstrated impairments in cognitive flexibility and monitoring of information in working memory compared to 20 nonusers, specifically demonstrating decrements in cognitive flexibility on a computer-administered global-local task and impaired working memory monitoring on a computer-administered n-back task.

Numerous studies have also shown effects of chronic methamphetamine use on a number of cognitive tasks [13-16]. A recent study indicated that chronic methamphetamine use was associated with a $40 \%$ prevalence of global neuropsychological impairment [17]. Nevertheless, despite the broad nature of such deficits, some of the most consistent and severe changes include specific impairments in working memory, attention, speed of information processing and executive function [14, 18-22]. Individuals with a history of methamphetamine use display decreases in working memory in the immediate recall
Table 1. Demographics of khat users and controls

\begin{tabular}{lll}
\hline & $\begin{array}{l}\text { Khat users } \\
(\mathrm{n}=32)\end{array}$ & $\begin{array}{l}\text { Controls } \\
(\mathrm{n}=26)\end{array}$ \\
\hline Males/females & $26 / 6$ & $13 / 13$ \\
Age, years & $24.25 \pm 5.32$ & $22.92 \pm 4.81$ \\
Years of education & $13.29 \pm 2.71$ & $12.35 \pm 3.38$ \\
\hline
\end{tabular}

Values are shown as numbers of subjects or means $\pm \mathrm{SD}$, as appropriate.

component of auditory verbal learning [23] and take 18$30 \%$ longer to complete the working memory components of the California Computerized Assessment Package [24].

Speed of information processing has fairly consistently been shown to be impaired in individuals who are chronic amphetamine users, and there is some evidence to suggest that this may persist during abstinence. Simon et al. [15] reported impairment in performance on the Digit Symbol Test [25] in their sample of current methamphetamine users, irrespective of the level of current drug use, versus matched controls. Johanson et al. [26] reported impaired performance on the Digit Symbol Substitution Test [27] in a sample of newly abstinent methamphetamine users, and Kalechstein et al. [28] reported that same finding on a similar measure, the Symbol Digit Modalities Test.

The purpose of the present pilot study was to assess whether chronic khat users would demonstrate similar decrements in working memory and speed of information processing, compared to control subjects, as those decrements seen in samples of chronic amphetamine users.

\section{Methods}

\section{Participants}

Subjects were 32 Yemeni individuals (26 men, 6 women) who were self-reported chronic khat users and 26 Yemeni individuals (13 men, 13 women) who reported no current use or history of regular khat use. The average age of the nonusers was 22.9 years, and the average age of the chronic users was 24.3 years. There was no significant difference in education between the two groups (table 1). All subjects were Arabic-speaking, Yemeni nationals. Subjects were recruited using flyers posted at Sana'a University and the surrounding community. Participants signed a consent form approved by the Sana'a University Research Ethical Committee and received a monetary incentive for their participation. Participants were eligible for the study if they were free from any medical conditions, free from mood disorders and psychiatric 
Table 2. Working memory and information processing speed scores among khat users and controls

\begin{tabular}{lllll}
\hline & $\begin{array}{l}\text { Khat users } \\
(\mathrm{n}=32)\end{array}$ & $\begin{array}{l}\text { Controls } \\
(\mathrm{n}=26)\end{array}$ & $\begin{array}{l}\mathrm{F} \\
(\text { d.f. }=57)\end{array}$ & p value \\
\hline Working memory & & & & \\
$\quad$ FDST & $4.50 \pm 1.34$ & $5.04 \pm 1.11$ & 0.19 & 0.665 \\
BDST & $2.66 \pm 1.38$ & $3.88 \pm 1.28$ & 3.08 & $0.007^{*}$ \\
$\begin{array}{l}\text { FDST + BDST } \\
\text { 7nformation processing speed } \\
\text { DSST }\end{array}$ & $8.92 \pm 1.81$ & 5.39 & $0.012^{* *}$ \\
\hline
\end{tabular}

Values are shown as means \pm SD. DSST $=$ Digit Symbol Substitution Test.

${ }^{*} \mathrm{p} \leq 0.01 ;{ }^{* *} \mathrm{p} \leq 0.05$.

conditions and were not taking any medications. Khat users had to have been chewing khat on a daily basis for at least 2 years and using no other drugs concurrently or historically. Khat users were allowed to use khat the day prior to testing to attempt to minimize any drug withdrawal effects. The typical usage pattern for khat is use in the afternoon to early evening. Cognitive testing occurred the following morning between 9.00 a.m. and approximately 11.00 a.m. The sessions for the study were conducted at Sana'a University Center for Gender and Development Studies.

\section{Procedures}

Working memory was assessed using the forward and backward digit span test (FDST and BDST). The digit span test is a measure of working memory, or more specifically of the ability to retain short-term, verbal material [27]. A string of single digits of varying length (from 2 to 8 digits in this study) are read to the research subject. The subject is then asked to recall the digits verbally. There are two sets of different digits for each digit length. This test was terminated when the subject failed to correctly recall both sets of digits for a particular digit length, with their score being derived directly from the most recent digit length for which the digits were recalled correctly. The BDST differs from the FDST in that the BDST requires the subject to recall the digits (from 2 to 7 digits in this study) in the reverse order from which they were originally read by the examiner.

Speed of information processing was assessed using the Digit Symbol Substitution Test. The Digit Symbol Substitution Test subtest of the Wechsler Adult Intelligence Scale - Third Edition is a visual scanning task that is a measure of psychomotor speed and manipulation of information, incidental learning of digitsymbol pairs and sustained effort [29]. The participant is given a sheet of paper with a decoding key containing 9 nonsense symbols paired with digits between 1 and 9. Underneath the key are rows of boxes, each associated with a digit. The subject responds to each digit by drawing the associated symbol in the box as quickly as possible. The outcome measure is the number of symbols correctly drawn in $90 \mathrm{~s}$. These measures have been used locally in Yemen, and instructions were all delivered in Arabic (the local language).

Working Memory and Information

Processing in Chronic Khat Users

\section{Results}

Analyses were conducted using multivariate analysis of covariance, with age and education as covariates. FDST and BDST scores were combined to yield an overall measure of working memory supraspan, in addition to separate analyses of FDST and BDST scores.

Contrary to expectation, there was no statistically significant difference in speed of information processing between the group of chronic khat users and the control group of abstainers from khat use $[\mathrm{F}(3,57)=0.819, \mathrm{p}=$ $0.369]$.

However, consistent with the pattern of performance seen in several studies of amphetamine users and the recently reported results of Colzato et al. [12], there was an observed decrement in working memory (FDST and BDST combined) in chronic khat users versus controls $[\mathrm{F}(3,57)=3.98, \mathrm{p}=0.012]$, primarily due to decrements in performance on the $\operatorname{BDST}[\mathrm{F}(3,57)=4.511, \mathrm{p}=0.007]$ (table 2). There were no significant group differences due to age $[\mathrm{F}(1,57)=0.007, \mathrm{p}=0.932]$. Despite the well-known positive correlation between level of education and performance on working memory measures, group differences attributable to level of education did not reach statistical significance at the $\mathrm{p}<0.05$ level on either the $\operatorname{BDST}[\mathrm{F}(1,57)=3.73, \mathrm{p}=0.06]$ or the FDST and BDST combined $[\mathrm{F}(1,57)=3.47, \mathrm{p}=0.07]$. The effect of gender was examined by $\chi^{2}$ analysis for both the BDST and combined FDST and BDST. In both cases, there were no significant independent effects of gender, as follows: $\chi^{2}$ for BDST $=9.38($ d.f. $=6), \mathrm{p}=0.15 ; \chi^{2}$ for combined FDST and $\mathrm{BDST}=5.92$ (d.f. $=6), \mathrm{p}=0.75$.

However, it should be noted that the magnitude of performance decrement seen in khat users in the present study, although statistically significant, is modest. The calculated effect size seen with the BDST was 0.4166 , and the effect size of the combined FDST and BDST variable was 0.4245 , both yielding effect sizes in the small to medium effect size range.

\section{Discussion}

The present pilot study indicates that khat use may have a long-term negative effect on working memory, particularly on digit backwards measures of short-term/ working memory. The finding is consistent with results recently reported by Wittmann et al. [30] and by Rendell et al. [31] in their sample of recently abstinent methamphetamine users, as well as the recent observations on 
impaired working memory monitoring seen in khat users reported by Colzato et al. [12]. However, it is unclear from the present study whether the observed performance decrement in working memory might represent a clinically significant abnormality or deficit. As noted in a recent review by Hart et al. [32], there has been a tendency in the methamphetamine literature to mislabel subtle but statistically significant differences between methamphetamine users and controls as 'deficits' or 'impairments', thereby implying substantial loss of cognitive function when, in fact, both experimental groups demonstrate performance that remains within the normal range. Further studies are needed to assess whether the observed difference is reflected in diminished performance on ecologically valid tasks involving working memory, such as driving an automobile or safely operating equipment.

There was no statistically significant impairment in performance on the information processing speed test used in the current study (the Digit Symbol Substitution Test). Although this raises the question of some dissociation between the effect of chronic khat use and chronic amphetamine use on information processing speed, this bears further study with a more robust sample size and multiple measures of processing speed with varying levels of task complexity. It may be that the Digit Symbol Substitution Test in this population is primarily a measure of psychomotor speed with minimal information processing demands. There is evidence in the amphetamine literature, for example, to suggest that chronic methamphetamine users do not have difficulty on tasks that require primarily psychomotor speed, such as Part A of the Trail Making Test $[15,33]$. Alternatively, it may be more likely that the Digit Symbol Substitution Test is a less specific test given that it involves multiple areas of cognitive functioning (including executive functions, psychomotor functioning, visuognosis and short-term memory) and is therefore less precise and less likely to reflect a subtle effect.

In a recent study that examined the cognitive performance of a mixed group of stimulant-dependent subjects (cocaine and/or methamphetamine users), Wittmann et al. [30] reported significantly lower scores on a digits backward task measure of short-term/working memory, but these subjects did not demonstrate lower scores on other measures of working memory (digits forward and the 2-back working memory task). Simon et al. [15] reported impairments in backward digit span in a subsample of very heavy methamphetamine users (those using more than 10 times per day). Individuals in this sample who used methamphetamine less frequently did not demonstrate impairment in backward digit span, however, although they demonstrated a mild generalized retrieval deficit on more difficult memory tasks. Other investigators have reported mixed results on digit span and similar working memory tasks with stimulant drug users. Simon et al. [21] reported that there were no apparent differences between a recent sample of subjects entering treatment for methamphetamine abuse and control subjects on the Backward Digit Span subtest of the Woodcock-Johnson Test Battery [34]; nor was there a significant difference on this measure between those subjects who were abstinent and those who had relapsed.

Decrements in performance on several psychomotor and verbal memory tasks lessen in methamphetaminedependent subjects after 3-14 months of abstinence [35], but these individuals continue to perform significantly worse on working memory tasks after 6-10 months of abstinence compared to controls [24]. Rendell et al. [31] reported impairments in short-term and working memory (as measured by digits forward and digits backward from the Wechsler scales) [27] in their sample of methamphetamine users tested after an average period of abstinence of 6 months. However, we note that some authors have showed no significant differences on working memory tasks for methamphetamine users in the initial phases of abstinence [28].

Notwithstanding the small sample size of the current study, these preliminary findings indicate possible longterm effects of khat use on one measure of working memory that is not only simple to administer but is also in common use in clinical practice. However, further studies may be warranted to replicate the results of this study with samples of other khat users in other parts of the world and also to examine whether individuals with more extensive khat use exhibit a greater degree of working memory decrement. The present study relied upon subjects' self-reported medical and psychiatric history, and subsequent studies should include review of medical records and more extensive, structured psychiatric interviews. There is a clear need for carefully controlled future studies to examine possible dose-response relationships with a large sample of khat users rather than simply comparing regular users versus nonuser controls as was done in the current preliminary study. Poly-drug use among khat users is uncommon in Yemen compared to other countries. Khat is not an illegal substance in that country; it is readily available, in common use and relatively inexpensive. Subsequent studies should nonetheless include urinary drug screening when this is practical to control for the effects of other drugs known to affect cognitive functioning. 
Colzato et al. [12] reported that khat users demonstrate performance deficits in the executive component of working memory consistent with impairment in the updating component of working memory, perhaps attributable to prefrontal cortex dysfunction and reduced dopamine levels in the striatum following long-term exposure to cathinone, similar to the effects of long-term exposure to amphetamines observed by Nordahl et al. [33] and Baicy and London [36]. This hypothesized mechanism of action should be thoroughly investigated in subsequent well-controlled studies.

Future studies should be added to the khat research agenda to examine the performance of khat users on a broader range of other measures of working memory as well as examining the effect of khat withdrawal on working memory functioning [37].

\section{Acknowledgements}

We gratefully acknowledge the support of our colleagues Najat Khalil and Molham Al-Habori at the University of Sana'a in Sana'a, Yemen. This study was supported in part by NIH Grant R21 DA024626 (Khat Research Program: Neurobehavioral Impact of Long-Term Use) and NIH Grant R03 TW007219 (Biobehavioral Mechanisms of Concurrent Tobacco and Khat).

\section{References}

$\checkmark 1$ Krikorian AD: Kat and its use: an historical perspective. J Ethnopharmacol 1984;12:115178.

-2 Warfa N, Klein A, Bhui K, Leavey G, Craig T, Stansfeld S: Khat use and mental illness: a critical review. Soc Sci Med 2007;65:309318.

3 Kalix P, Braenden O: Pharmacological aspects of the chewing of khat leaves. Pharmacol Rev 1985;37:149-164.

4 Kalix P: Cathinone, a natural amphetamine. Pharmacol Toxicol 1992;70:77-86.

5 Kalix P: Catha edulis, a plant that has amphetamine effects. Pharm World Sci 1996;18: 69-73.

6 6 Toennes SW, Harder S, Schramm M, Niess C, Kauert GF: Pharmacokinetics of cathinone, cathine and norephedrine after the chewing of khat leaves. Br J Clin Pharmacol 2003;56:125-130.

7 Review of the pharmacology of khat. Report of a WHO advisory group. Bull Narc 1980; 32:83-93.

8 Graziani M, Milella M, Nencini P: Khat chewing from a pharmacological point of view: an update. Subst Use Misuse 2008;43: 762-783.

-9 Fleckenstein A, Haughey H, Metzger R, Kokoshka J, Riddle E, Hanson J, et al: Differential effects of psychostimulants and related agents on dopaminergic and serotonergic transporter function. Eur J Pharmacol 1999; 382:45-49.

10 Rothman R, Vu N, Partilla J, Roth B, Hufeisen S, Compton-Toth $B$, et al: In vitro characterization of ephedrine-related stereoisomers at biogenic amine transporters and the receptorome reveals selective actions as norepinephrine transporter substrates. J Pharmacol Exp Ther 2003;307:138-145.
Colzato LS, Ruiz MJ, van den Wildenberg WP, Bajo MT, Hommel B: Long-term effects of chronic khat use: impaired inhibitory control. Front Psychol 2011;1:1-5.

12 Colzato LS, Ruiz MJ, van den Wildenberg WP, Hommel B: Khat use is associated with impaired working memory and cognitive flexibility. PLos One 2011;6:1-6.

13 Rogers RD, Everitt BJ, Baldacchino A, et al: Dissociable deficits in the decision-making cognition of chronic amphetamine abusers, opiate abusers, patients with focal damage to prefrontal cortex, and tryptophan-depleted normal volunteers: evidence for monoaminergic mechanisms. Neuropsychopharmacology 1999;20:322-339.

14 Salo R, Nordahl TE, Possin K, Leamon M, Gibson DR, Galloway GP, et al: Preliminary evidence of reduced cognitive inhibition in methamphetamine-dependent individuals. Psychiatry Res 2002;111:65-74.

-15 Simon SL, Domier C, Carnell J, Brethen P, Rawson R, Ling W: Cognitive impairment in individuals currently using methamphetamine. Am J Addict 2000;9:222-231.

16 Ornstein TJ, Iddon JL, Baldacchino AM, Sahakian BJ, London M, Everitt BJ, et al: Profiles of cognitive dysfunction in chronic amphetamine and heroin abusers. Neuropsychopharmacology 2000;23:113-126.

$\checkmark 17$ Rippeth JD, Heaton RK, Carey CL, Marcotte TD, Moore DJ, Gonzalez R, et al: Methamphetamine dependence increases risk of neuropsychological impairment in HIV infected persons. J Int Neuropsychol Soc 2004; $10: 1-$ 14.

18 Gonzalez R, Rippeth JD, Carey CL, Heaton RK, Moore DJ, Schweinsburg BC, et al: Neurocognitive performance of methamphetamine users discordant for history of marijuana exposure. Drug Alcohol Depend 2004; 76:181-190.
19 Woods SP, Rippeth JD, Conover E, Gongvatana A, Gonzalez R, Carey CL, et al: Deficient strategic control of verbal encoding and retrieval in individuals with methamphetamine dependence. Neuropsychology 2005; 19:35-43.

20 Sim T, Simon SL, Domier CP, et al: Cognitive deficits among methamphetamine users with attention deficit hyperactivity disorder symptomatology. J Addict Dis 2002;21:7589.

21 Simon SL, Domier CP, Sim T, Richardson K, Rawson RA, Ling W: Cognitive performance of current methamphetamine and cocaine abusers. J Addict Dis 2002;21:61-74.

-22 Paulus MP, Hozack NE, Zauscher BE, et al: Behavioral and functional neuroimaging evidence for prefrontal dysfunction in methamphetamine-dependent subjects. Neuropsychopharmacology 2002;26:53-63.

23 Volkow ND, Chang L, Wang GJ, Fowler JS, Leonido-Yee M, Franceschi D, et al: Association of dopamine transporter reduction with psychomotor impairment in methamphetamine abusers. Am J Psychiatry 2001;158: 377-382.

24 Chang L, Ernst T, Speck O, Patel H, DeSilva $M$, Leonido-Yee M, et al: Perfusion MRI and computerized cognitive test abnormalities in abstinent methamphetamine users. Psychiatry Res 2002;114:65-79.

25 Wechsler D: Manual for the Wechsler Adult Intelligence Scale-Revised. New York, Psychological Corporation, 1981.

26 Johanson C, Frey K, Lundahl L, Keenan P, Lockhart N, Roll J, Galloway G, Koeppe R, Kilbourn M, Robbins T, Schuster C: Cognitive function and nigrostriatal markers in abstinent methamphetamine abusers. Psychopharmacology 2006;185:327-338. 
27 Wechsler D: Wechsler Adult Intelligence Scale-III. New York, Psychological Corporation, 1997.

28 Kalechstein AD, Newton TF, Green M: Methamphetamine dependence is associated with neurocognitive impairment in the initial phases of abstinence. J Neuropsychiatry Clin Neurosci 2003;15:215-220.

29 Kaplan E, Fein D, Morris R, Delis D: WAIS-R as a Neuropsychological Instrument. San Antonio, Psychological Corporation, 1991.

30 Wittmann M, Leland D, Churan J, Paulus M: Impaired time perception and motor timing in stimulant-dependent subjects. Drug Alcohol Depend 2007;90:183-192.
31 Rendell P, Mazur M, Henry J: Prospective memory impairment in former users of methamphetamine. Psychopharmacology 2009;203:609-616.

32 Hart C, Marvin C, Silver R, Smith E: Is cognitive functioning impaired in methamphetamine users? A critical review. Neuropsychopharmacology 2012;37:586-608.

33 Nordahl TE, Salo R, Leamon M: Neuropsychological effects of chronic methamphetamine use on neurotransmitters and cognition: a review. J Neuropsychiatry Clin Neurosci 2003;15:317-325.

34 Woodcock R, Johnson M: Woodcock-Johnson Psychoeducational Battery. Allen, DLM Teaching Resources, 1977.
35 Volkow ND, Chang L, Wang GJ, Fowler JS, Franceschi D, Sedler M, et al: Loss of dopamine transporters in methamphetamine abusers recovers with protracted abstinence. J Neurosci 2001;21:9414-9418.

36 Baicy K, London E: Corticolimbic dysregulation and chronic methamphetamine abuse. Addiction 2007;102:5-15.

37 Hoffman R, al'Absi M: Khat use and neurobehavioral functions: suggestions for future studies. J Ethnopharmacol 2010;132: 554-563. 